\title{
Эрика ЮРГЕНСОН
}

\section{ИЗМЕНЕНИЕ МИНЕРАЛЬНОГО СОСТАВА ОТЛОЖЕНИИ НА ПОВЕРХНОСТЯХ ПЕРЕРЫВА В СИЛУРЕ ЭСТОНИИ}

Силурнйский разрез Прибалтики характеризуется многочисленными стратиграфическими пробелами, ярко выраженными на поверхностях перерыва. Специальных работ по их изучению проведено еще очень мало. Все же имеется несколько публикаций, рассматривающих главным образом морфологические особенности поверхностей перерыва (Kupffer, 1870; Orviku, 1940; Орвику, 1960; Эйнасто, 1964). Наиболее обобщающий подход к изучению стратиграфических пробелов и седиментационных перерывов был недавно предложен Э. Пиррусом и Р. Эйнасто (1987). Они рассматривали многие вопросы терминологии, а также сущность иерархической классификации стратиграфических пробелов.

В данной работе изложены первые результаты исследования некоторых вопросов, связанных с общим ходом седиментационного процесса в силуре, а также изменений состава терригенного материала и аутигенного минералообразования на поверхностях перерыва. Материал для исследования собран из восьми скважин, охватывающих практически весь разрез силура в Эстонии (рис. 1). Было изучено 50 поверхностей
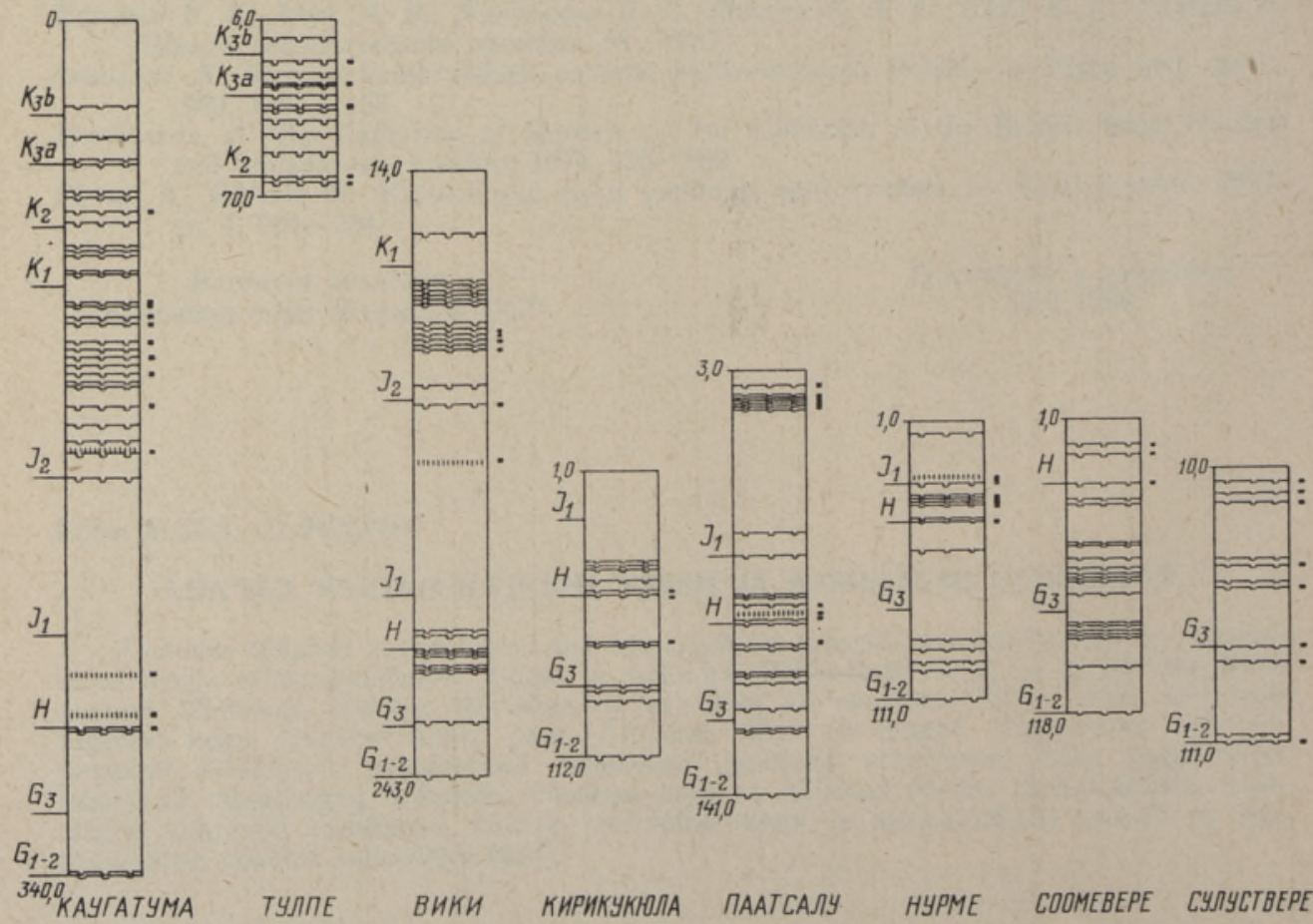

Рис. 1. Распространение поверхностей перерывов в разрезах буровых скважин силура Эстонин. 1 - поверхности, 2 - метабентонитовые прослон, 3 - места отбора парных проб. 
перерыва, опробованы как подконтактовые, так и надконтактовые слон, выделен терригенный материал из карбонатных пород, проведены гранулометрические и минералогические анализы 136 образцов по методике, описанной автором ранее (Юргенсон, 1976, 1987). Аутигенные минералы определены оптическим и рентгенометрическим методами (ИГ АН ЭССР, апалитик Т. Калласте).

Мы не проводили специальных морфологических исследований поверхностей перерыва из-за трудностей прослеживания их на ограниченном сечении керна. Но, имея в виду возможные связи между морфологией и изменением минерального состава, пытались определить общий характер поверхностей исходя из морфологической классификации Р. Эйнасто (1964), разработанной для роотсикюлаского горизонта. Можно сказать, что преобладающая часть исследованных нами поверхностей перерыва, находящихся, в основном в глинистых известняках - несглаженно-неровная, примерно на $10 \%$ изъеденная глубокими карманами и ходами илороющих организмов. Такне карманы (до 10 см и больше) присущи многим поверхностям райккюлаского и яагарахуского горизонтов. Около 1/5 исследованных нами поверхностей можно считать сглаженно-ровными, особенно в нижней части адавереского и в паадласком горизонтах, где лежащие на поверхностях слои обычно представлены обломочными известняками. Остальные исследованные поверхности либо несглаженно-ровные, либо сглаженно-неровные. Морфология поверхностей, особенно сглаженность, может изменяться и в зависимости от литофациальных условий.

Исследование поверхностей перерывов в фациальном плане бассейна показывает, что большинство перерывов в седиментации четко и конкретно выражены в литоральной и шельфовой зонах. С глубиной бассейна роль гидродинамических и геохимических факторов падает - уменьшается карбонатонакопление и увеличивается гомогенность осадочного матернала, беднеет состав как аутигенных, так и аллотигенных (терригенныу) минералов. Их наличие устанавливается только тщательным исследованием последовательности слоев (цикличность и т. п.) и отдельных компонентов.

Самым крупным из исследованных нами пробелов является контакт ордовика и силура, который, по предложенной иерархической классификации (Пиррус, Эйнасто, 1987), трактуется как мезопробел в пределах всего седиментационного бассейна. Его объем в Северной Прибалтике ограничивается лишь частями верхнеордовикского (поркуниского) и нижнесилурийского (юуруского) горизонтов, в южном же направлении он постепенно увеличивается, охватывая в Литве $1-2$ горизонта нижнего силура.

Преобладающая часть залегающих под этим пробелом верхнеордовикских слоев представлена мелководными отложениями, часто лагунными (доломиты, оолитные и детритные известняки, биогермы, известковые алевролиты), образовавшимися в стадии регрессии моря. Над ними трансгрессивно залегают отложения нижнего силура, представленные в основном глинистыми мелкодетритовыми известняками и мергелями.

Прекращение осадконакопления и размыв отложений на границе ордовика и силура зафиксированы в разрезе Северной Прибалтики пиритизированной поверхностью перерыва. Зона пиритизации под этой поверхностью достигает в некоторых разрезах Средней Эстонии (скв. Эйамаа) $10-15$ см и местами пересекается трещинами, заполненными кальцитом. Содержание терригенного материала в известняках и доломитах подконтактовых слоев составляет $10-20 \%$, иногда и больше, в песчано-алевритовой фракции $(0,01-0,5$ мм - около $50 \%$, остальная часть представлена пелитом. В минеральном составе песчано-алеврито- 
вой фракции преобладают кварц (больше $70 \%$ ) и полевые шпаты (25$28 \%$ ). Содержание тяжелых прозрачных минералов (циркон, гранат, турмалин) очень низкое - меньше $0,1 \%$ (рис. 2, II), ведущее место занимает циркон. По сравнению с лежащими глубже слоями значение циркона увеличивается (рис. 2, I), а граната уменьшается.

В подконтактовых слоях более часто встречаются аутигенные образования, в основном пирит и халцедон. Максимальное содержание пирита может достигать $10 \%$ от всей породы на самой поверхности и с глубиной постепенно убывает. Но иногда встречаются небольшие конкрециевидные образования и глубже - т. е. в зоне импрегнации среди рассеянных в породе тонких кристалликов. Диаметр кристаллов пирита колеблется от 0,02 до 5 мм (Юргенсон, 1960). Большинство из них относится к мелкоалевритовой фракции. В песчано-алевритовой фракции нерастворимого остатка пирит составляет около $80 \%$ (рис. 2, II). Содержание $\mathrm{Fe}_{2} \mathrm{O}_{3}$ общ в зоне интенсивной импрегнации поверхности перерыва доходит до $20 \%$, что в 10 раз превышает его фоновое содержание в силурийских известняках и доломитах Северной Прибалтики. Рентгеноструктурный анализ показал, что пирит хорошо кристаллизовался при $d=2,696,2,417$ и $1,629 \AA$.

Аутигенный кремнезем встречается в подконтактовом слое пограничной поверхности перерыва в виде небольших скоплений кристалликов халцедона (диаметр около 0,03 мм), неравномерно распределенных среди карбонатного материала и кристалликов пирита. По данным рентге-

\section{$\begin{array}{lllllllllllll}0 & 20 & 40 & 60 & 80 & 100 \% & 0 & 20 & 40 & 60 & 80 & 100 \%\end{array}$ IX

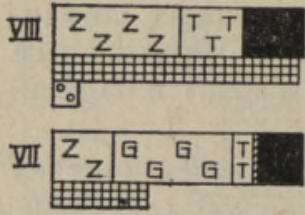 \\ \begin{tabular}{|l|l|l|}
\hline$Z_{2} z^{G}$ & ${ }_{G}{ }_{G}$ \\
\hline
\end{tabular} \begin{tabular}{|l|l|l|l|}
\hline$Z^{2} z^{Z}$ & $G_{G}^{G}$ & $T$ \\
\hline
\end{tabular} 4}

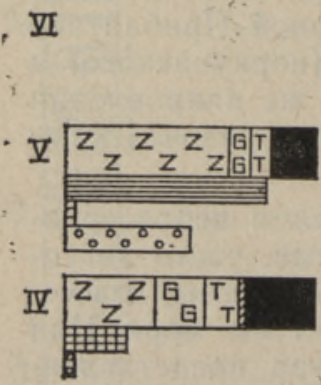

III

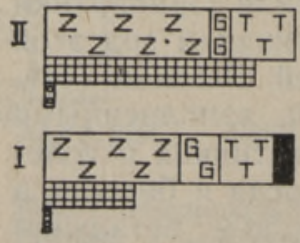

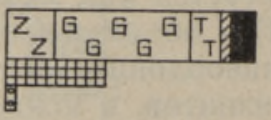
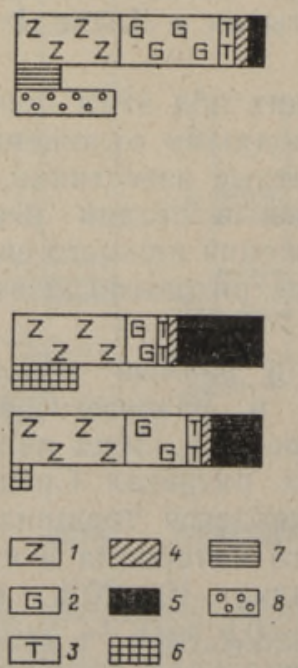

Рис. 2. Содержание основных аутигенных и тяжелых аллотигенных минералов. Разрез скв. Сулуствере: I - поркуниский горизонт, гл. $111,0 \mathrm{~m}$. II - граница ордовика и силура гл. 110,3 м, подконтактовые (левая сторона) и надконтактовые слон (правая сторона); III - юуруский горизонт, гл. 109,7 м; Соомевере: IV - райккюлаский горнзонт, гл, 14,3 м; V - граница адавереского и райккюлаского горизонта, гл. 13,3 м, подконтактовые (л. с.) и надконтактовые слои (п. с.); VI - адавереский горизонт, гл. 10,0 м; Паатсалу; VII - яагарахуский горизонт, гл́. 16,5 м; VIII - поверхность перерыва на гл. 15,0 м, подконтактовые (л. с.) и надконтактовые (п. с.) слон; IX - яагарахуский горизонт, гл. 9,5 м. 1 - циркон, 2 гранат, 3 - турмалин, 4 - амфиболы и пироксены, 5 - остальные тяжелые аллотигенные минералы, 6 пирит, 7 - гематит и гидрогематит, 8 - халцедон. 
ноструктурного анализа, они представляют собой хорошо выкристаллизованный кварц $(d=3,33 \AA)$, который только по некоторым оптическим показателям (радиально лучистое погасание при скрещенных николях, немного пониженные показатели преломления) сохранил следы аутигенного происхождения. Халцедон, как и пирит, - образование явно диагенетическое.

Залегающие непосредственно над поверхностью перерыва глинистые известняки силура (юуруский горизонт) содержат терригенного материала больше, чем нижележащие слои, но песчано-алевритовой фракции в них меньше (около $30 \%$ из некарбонатного компонента). Основная часть песчано-алевритовой фракции сложена кварцем (52\%), полевых шпатов больше, чем в терригенном материале подконтактовых пород $(47 \%)$. Содержание тяжелых прозрачных минералов может быть до 20 раз больше, чем в подконтактовых слоях. Значение циркона и турмалина среди них уменьшается (рис. 2, II), а содержание граната увеличивается $(25 \%)$. Кроме того, встречаются амфио́олы, пироксены и титанистые минералы. Роль аутигенных минералов уменьшается.

Содержание пирита в песчано-алевритовой фракции нерастворимого остатка в среднем около $10 \%$. Он распределен равномерно по всей породе в виде тонких кристалликов (диаметр около 0,02 мм). Других аутигенных минералов в надконтактовом слое, а также в породах выше (рис. 2 , II, III), не установлено.

Следующий по длительности пробел, исследованный нами в силурийском разрезе Северной Прибалтики, находится на границе райккюлаского и адавереского горизонтов. По предложенной классификации его можно рассматривать как мезо- или микропробел. Объем отсутствующих слоев на территории Эстонии ограничивается отдельными пачками. В центральной части седиментационного бассейна он постепенно уменьшается в юго-западном направлении, а в юго-восточной части, где нижние горизонты силура отсутствуют, он переходит в крупный макропробел. Этот пробел в Эстонии связан со среднелландоверийской регрессией и позднелландоверийской трансгрессией. Оба они прослеживаются в многочисленных пиритизированных поверхностях перерыва и связанных с ними конгломератовых прослоях нижней части адавереского горизонта.

Основные изменения состава терригенного материала отмечаются в пограничной поверхности между райккюласким и адавереским горизонтами. По своей морфологии она в большинстве разрезах сглаженная неровная, с наличием ходов типа трипанитес. Пиритизация на поверхности интенсивная, но не достигает существенной глубины $(2-3 \mathrm{~cm})$. В районах распространения вторичной доломитизации (в Центральной и Северо-Восточной Әстонии) пирит заменен гематитом и гидрогематитом. Непосредственно под поверхностью перерыва в большинстве случаев залегает мелкодетритовый известняк (доломит), содержащий терригенного материала $10-20 \%$. Состав залегающих над пробелом известняков адавереского горизонта более глинистый, детритовый или обломочный.

Содержание песчано-алевритовой фракции в терригенном подконтактовом слое сравнительно большое (до 50\%). Представлена она преимущественно кварцем и полевыми шпатами в почти равных количествах. Зерна кварца часто носят следы разъедания, а иногда и небольшие нарость. вторичного кремнезема. Содержание тяжелых прозрачных минералов небольшое $(0,01 \%)$. Преобладает циркон (рис. $2, \mathrm{~V})$, которого значительно больше, чем в нижележащих слоях райккюлаского горизонта (рис. 2, IV). Реже встречаются гранат и турмалин, у которых обнаружены следы растворения.

Среди аутигенных минералов основную часть составляют пирит 
(около $4 \%$ от всей породы) и халцедон $(1-3 \%)$. В алевритовой фракции их содержится в среднем 66 и $35 \%$ соответственно. Реже присутствуют барит, сфалерит, галенит, гематит и гидрогематит (сотые доли процента). Пирит в подповерхностном слое встречается в виде мелкокристаллических агрегатов, глубже, в зоне импрегнации, - в виде отдельных кристалликов диаметром около 0,02 мм.

На границе райккюлаского и адавереского горизонтов состав терригенного материала, особенно тяжелых прозрачных минералов, заметно изменяется. Содержание алевритовой фракции уменьшается почти вдвое, особенно в Средней и Восточной Әстонии. Соотношение кварца и полевых шпатов изменяется мало. Содержание тяжелых прозрачных минералов увеличивается в $10-20$ раз. Во всех исследованных разрезах гранат преобладает над цирконом (рис. 2, VI). Такое соотношение основных тяжелых минералов характерно для терригенного материала всего адавереского и большей части яаниского горизонтов на севере и востоке Прибалтийского бассейна, что, по-видимому, свидетельствует об изменениях в исходном материале и в источниках сноса (Юргенсон, 1987). Из остальных аллотигенных тяжелых минералов присутствуют турмалин, биотит, титанистые минералы, амфиболы и пироксены, корунд и др. Зерна со следами растворения встречаются редко.

Содержание аутигенных минералов (особенно кремнезема) в надконтактовых слоях зависит, в данном случае, от фациальных условий осадконакопления. Бедные терригенным материалом карбонатные отложения шельфовой зоны зодержат много аутигенного кремнезема - до $10 \%$ от всей породы (больше $80 \%$ от песчано-алевритовой фракции н. о.). Содержание кремнезема в отложениях более глубоководных фаций резко уменьшается, а местами - полностью отсутствует. Различия в содержании пирита между под- и надконтактовыми слоями менее значительны, чем в слоях на границе ордовика и силура. В среднем содержание пирита в вышележащих отложениях в два раза меньше, чем в зоне импрегнации. Встречается он, в основном в виде рассеянных тонких кристалликов диаметром около 0,02 мм или в виде импрегнации на гальках в конгломератовых прослоях. В случае присутствия гематита и гидрогематита их количество в надконтактовых слоях меньше, чем в зоне импрегнации. Из остальных аутигенных минералов можно назвать барит и глауконит, содержание которых в алевритовой фракции некарбонатной части обычно не превышает $1 \%$.

Кроме вышеописанных границ, являющихся стратиграфическими, исследовали изменения состава отложений еще 48 поверхностей перерыва, соответствующих пробелам более мелкого порядка (микро- или нанопробелы по предложенной классификации). Различия в составе терригенного материала под- и надконтактовых слоев здесь менее выразительны, однако в целом имеют аналогичную другим пробелам направленность.

Большинство поверхностей перерыва с пиритовой импрегнацией сохранилось в чистых или слабоглинистых породах. Подконтактовые слои содержат хорошо отсортированный терригенный материал, где доля песчано-алевритовой фракции в два раза выше, чем в надконтактовых слоях. Надконтактовые слои характеризуются плохой сортированностью и хорошей окатанностью зерен. Диаметр аллотигенных прозрачных тяжелых минералов всегда меньше в подконтактовых слоях, причем нередко зерна имеют следы растворения, резъедания и нарастания. Все это говорит о различных темпах осадконакопления в под- и надконтактовых слоях. При медленном темпе осадконакопления диагенетические процессы в подконтактовых отложениях имели гораздо бо́льшее значение, чем при интенсивном накоплении в надконтактовых отложениях, образовавшихся в трансгрессивных условиях. 
В минеральном составе песчано-алевритовой фракции есть некоторые различия, характерные для большинства поверхностей перерывов. Количество видов аллотигенных прозрачных тяжелых минералов и их процентное содержание всегда больше в надконтактовых слоях. Всегда встречается множество малоустойчивых амфиболов и пироксенов, а также гранат, турмалин и титанистые минералы. Подконтактовые слои отличаются, как правило, более высоким содержанием циркона (рис. 2, VIII). Но все же надо отметить, что минеральный состав контактирующих слоев имеет некоторые особенности, зависящие не от процессов формирования пробелов, а от общих измененнй состава терригенного материала в том или ином горизонте. Так, например, если в райккюласком горизонте полевые шпаты преобладают над кварцем, то они преобладают и в подконтактовых слоях поверхностей перерыва, хотя здесь они сильно изменены, вплоть до образования агрегатов. Аналогичная картина наблюдается в адавереском и яаниском горизонтах и в подконтактовых слоях, хотя в последних гранат имеет следы растворения, а преобладающим минералом опять-таки является циркон. Начиная с паадлаского горизонта в минеральном составе бо́льшее значение приобретает биотит. Он появляется и у поверхностей перерыва, особенно в надконтактовых слоях, в виде округленных чешуек.

Судя по предварительным данным, можно сказать, что нет определенной связи между морфологией поверхности перерыва и минеральным составом терригенного материала контактирующих слоев. Подконтактовые слои имеют максимально обедненный минеральный состав терригенного материала лишь у сглаженно-неровных поверхностей. Неимпрегнированные поверхности перерыва обнаруживались главным образом по резкому изменению состава пород: подконтактовые слои в большинстве случаев сложены известняками, а надконтактовые - мергелями. В терригенном материале подконтактовых слоев иногда наблюдаются следы растворения и изменения, что указывает на медленное осадконакопление или даже на длительный перерыв. Содержание аутигенных минералов не превышает фоновое.

Большинство исследованных нами поверхностей перерыва характеризуется пиритовой импрегнацией. Қак уже отмечалось, максимальная концентрация пирита наблюдается на самой поверхности пробелов и вокруг ходов илоедов. С глубиной его содержание постепенно уменьшается. Глубина зоны импрегнации в большинстве случаев остается в пределах $1-3$ см. Такое распределение пирита в породе свидетельствует как о концентрации, так и о выпадении соединений железа на контакте двух сред. Содержание $\mathrm{Fe}_{2} \mathrm{O}_{3}$ общ в зоне импрегнации большинства поверхностей колеблется от 5 до $8 \%$. Образование гематита и гидрогематита было обнаружено и во многих поверхностях райккюлаского и адавереского горизонтов зоны вторичной доломитизации в Средней и Восточной Эстонии (разрезы Соомевере и Сулуствере) и лишь в редких случаях в Западной Эстонии (разрез Каугатума, гл. 76,2 м) на границе роотсикюлаского и паадлаского горизонтов, где они контактируют с пиритом. В данном случае происхождение гематита еще не совсем ясно. Возможно, что главную роль здесь играли не вторичные (катагенетические) процессы, а первичные, так как вторичной доломитизации не обнаружено. В разрезах Каугатума (гл. 259,4 м) адавереского и Тулпе (гл. 36,6 м) паадлаского горизонтов отдельные сравнительно ровные пиритизирован. ые поверхности покрыты гидрогетитовым слоем мощностью 2 -3 мм. Сами поверхности вмещаются в мергелях. Возможно, это призиак вторичного окисления, но не исключена возможность, что гидрогетит является первичным и сохранился благодаря достаточно глинистым отложениям.

Из других аутигенных минералов, установленных в зоне импрегнации 
исследованных поверхностей перерыва, можно назвать сфалерит - в виде единичных кристаллов в яагарахуском (разрез Каугатума, гл. 118,6 и 129,3 м) и каугатумаском (разрез Тулпе, гл. 8,3 м) горизонтах. Барит встренается во всех исследованных нами разрезах - в райккюласком, яагарахуском и каугатумаском горизонтах, отложения которых образовались, в основном, в регрессивной стадии осадконакопления. Однако содержание сфалерита и барита не превышает тысячных долей процента (от всей породы). В одном горизонте - курессаареском (разрез Тулпе, гл. 24,7 м) - были определены агрегаты серицита.

Подытоживая вышеизложенное об изменениях состава силурийских карбонатных пород на поверхностях перерыва, можно сделать следующие основные выводы:

1. Независимо от продолжительности перерывов всегда существуют уловимые различия в составе ниже- и вышележащих слоев. Кроме структурных изменений карбонатного компонента, эти изменения достаточно четко отражаются в составе как терригенного, так и аутигенного материала.

2. Как правило, терригенного материала больше в надконтактовых слоях, а песчано-алевритовой фракции - в подконтактовых.

3. Аутигенное минералообразование всегда более развито в подконтактовых слоях и не только в виде пиритовой импрегнации, но и в виде других минералов (гематит, гидрогематит, халцедон, барит, серицит).

4. Терригенный материал в подконтактовых слоях более изменен и сложен преимущественно устойчивыми минералами (кварцем, цирконом). На минералах часто встречаются следы растворения и разъедания.

5. Терригенный материал в надконтактовых слоях более разнообразен: здесь значительно больше слюд, богаче набор тяжелых прозрачных минералов.

6. Судя по изменениям в минеральном составе, можно предполагать, что осадконакопление перед перерывами, особенно перед более длительными, происходило более медленно (стадия регрессии), а после перерыва - более интенсивно (стадия трансгрессии).

\section{ЛИТЕ РА Т У РА}

Орвику $K$. K. О стратиграфии волховского и кундаского горизонтов в Эстонии. - Тр. Ин-та геол. АН ЭССР, V, 1960, 45-87.

Пиррус Э., Эйнасто Р. Классификация стратиграфических пробелов и седиментационных перерывов в палеозое Прибалтики. - Изв. АН ЭССР. Геол., 1987, 36, № 1, $36-45$.

Эйнасто Р. Э. К вопросу о классификацин и формировании поверхностей перерыва. - В кн.: Литология палеозойских отложений Эстонии. Таллин, 1964, 123-131.

Юргенсон Э. А. Размещение соединений железа в осадочных коренных породах Эстонской ССР. - Ежегодн. Об-ва естествоиспытателей при АН ЭССР, 1960, 53, 3045.

Юргенсон Э. А. Опыт исследования нерастворимого остатка карбонатных пород. - В кн.: Методика и интерпретация результатов минералогических и геохимических исследований. Вильнюс, 1976, 31-36.

Юргенсон Э. А. Осадконакопление в силуре Прибалтики. Таллин, 1987.

Kupffer, A. Ueber die chemische Constitution der baltisch-silurischen Schichten. - Arch. Naturk. Liv-, Ehst- und Kurland, 1870, Ser. 1, 5, 69-194.

Orviku, K. Lithologie der Tallinna-Serie (Ordovizium, Estland). I. - Acta et Comm. Univ. Tartuensis, A XXXVI. Tartu, 1940.

Ннститут геологии

Академии наук Эстонской ССР
Поступила в редакцию 13/I 1986 


\section{KATKESTUSPINDADEST TINGITUD MUUTUS EESTI SILURI SETETÉ MINERALOOGILISES KOOSTISES}

Eesti siluri karbonaatses läbilōikes esineb arvukalt katkestuspindasid. Nende ümbruse setete mineraloogiline uurimine näitas, et pindade alla jäävaid kihte iseloomustavad rohked autigeensed mineraalid (püriit, hematiit, kaltsedon, barüüt jt.) ja vähesed vastupidavamad terrigeensed mineraalıd (kvarts, tsirkoon). Katkestuspindadele jäävais kihtides on autigeenseid mineraale vähem, seevastu terrigeensete mineraalide koostis on mitmekesisem. Muutused koostises on seda suuremad, mida pikemaajalisem on olnud katkestus sedimentatsioonis.

\section{Erika JORGENSON}

\section{THE CHANGE OF MINERALOGICAL COMPOSITION AT THE DISCONTINUITY SURFACES IN THE SILURIAN BEDS OF ESTONIA}

Several discontinuity surfaces of the Silurian carbonate section in Estonia have been investigated (Fig. 1), among these, the stratigraphically important surfaces at the boundary of Ordovician and Silurian, and the Middle and Upper Llandovery. More or less extensive changes take place in the allothigenous and authigenous mineral composition at the discontinuity surfaces. The underlying beds are characterized by an abundance of authigenous minerals such as pyrite (pyritic impregnation), hematite, chalcedon, baryte, etc. (Fig. 2). The main part of allothigenous minerals is represented by coarsegrained quartz. Zircon is often the only mineral in the heavy fraction. The overlying beds contain, as a rule, less authigenous and more allothigenous minerals. The changes on discontinuity surfaces are more clearly developed when the hiatus lasted for a long time, and the regressive phase of sedimentation was followed by the transgressive one. 